\title{
Tigeciclina como terapia en neumonías
}

\author{
Tigecycline as a treatment for pneumonia
}

$\mathrm{E}$ n el número actual de Revista Chilena de Infectología, Moya Cordero y cols. (pág. 587), presentan una revisión sistemática sobre la eficacia y seguridad de tigeciclina en infecciones respiratorias, basada en el análisis de cuatro ensayos clínicos (tres en neumonía adquirida en la comunidad y uno en neumonía nosocomial). En dicha revisión, se demuestra no inferioridad de tigeciclina respecto al antimicrobiano comparador (levofloxacina) en el tratamiento de neumonías adquiridas en la comunidad, lo que no se observa en neumonías nosocomiales, donde tigeciclina resulta tener una eficacia inferior respecto al antimicrobiano comparador (imipenem/cilastatina).

Cabe destacar que si bien tigeciclina está aprobada por la FDA (Food and Drug Administration, por sus siglas en inglés) para el tratamiento de neumonías adquiridas en la comunidad, NO debe emplearse de forma rutinaria para el tratamiento de esta patología, sino de forma excepcional. Al decidir el tratamiento empírico de una infección, se deben considerar múltiples factores: cuáles son los patógenos más probables, si el paciente tiene factores de riesgo para resistencia antimicrobiana, presencia de co-morbilidades, cuál es la evidencia de la eficacia de las distintas alternativas terapéuticas, el potencial favorecimiento de la resistencia antimicrobiana al antibacteriano elegido, el perfil de seguridad y costo, entre otros. Para el tratamiento de infecciones respiratorias adquiridas en la comunidad existen múltiples alternativas de antimicrobianos que cubren los agentes patógenos más frecuentemente aislados en estas infecciones, son efectivas, seguras y de menor costo que tigeciclina. Además, hay que recordar que en Chile el ISP (Instituto de Salud Pública) no ha aprobado la indicación de tigeciclina para el tratamiento de neumonía adquirida en la comunidad.

Isabel Domínguez

Co-Editora

Sección Antimicrobianos. 